Research Station has been particularly concentrated on the design of trawlers which will freeze part of the catch rather than on factory ships to freeze and process all of it at sea, and a model of one of the first vessels of this type to operate commercially was exhibited.

When frozen fish is used on any large scale the problem of thawing for further processing becomes a matter of very considerable importance. The thermal diffusivity of wet fish is very much less than that of frozen fish, and hence the thawing of a block of frozen fish in warm air is a self-retarding process. Also the temperature gradient permissible in such a process is limited by the need to minimize the spoilage of the fish already thawed. This has led to examination of dielectric heating as a means of thawing, and a practicable technique has been worked out. A pilot plant of $6-\mathrm{kW}$. output operating at $36 \mathrm{Mc} / \mathrm{s}$. was on show. In this, frozen fish was carried on a conveyor belt between the plates of a condenser and 2-st. blocks were thawed in about $15 \mathrm{~min}$. Equipment of this type developed by the Torry Research Station has recently been put into commercial operation.

Despite the attention given to frozen fish, work on wet fish has been by no means neglected. A number of exhibits were concerned with the effect of tempera. ture on spoilage by reference to the chemical and bacteriological changes involved. The Humber Laboratory has been particularly concerned with the temperature of fish throughout the chain of distribution and has conducted temperature surveys at all stages from dock side to retail shop. This work has entailed the development of a number of special instruments, notable among which is a spear-type resistance thermometer in which the resistance element is contained within a hypodermic needle. For making temperature measurements by thermocouple on board moving vehicles, the conventional electronic self-balancing potentiometer is not a very suitable instrument. It is too large and its power consumption is too great. The Humber Laboratory has developed a small, battery-operated potentiometer in which balance is indicated by a 'magic eye', and this has been used successfully for many measurements on lorries. Another simple and effective instrument is the 'temperature indicator' which shows a sharp change in colour when it exceeds a given temperature. This device consists of a tube of $1 \mathrm{ml}$. capacity containing two aqueous solutions separated by a frozen non-aqueous layer.
The Torry Research Station has long been concerned with the smoking of fish, and when the Humber Laboratory was opened most of the applied work on this subject was transferred to Hull. The 'Torry kiln' has made considerable strides towards becoming the conventional piece of apparatus for smoking fish. Examples of the wide range of smoked products that can be made in a Torry kiln were on show together with sectioned models of both Torry and traditional kilns. The Humber Laboratory has devoted considerable effort to the question of the more efficient production of wood smoke, and has developed a continuous, automatically controlled smoke producer which uses a fluidized bed of sawdust. Tests have also been carried out to evaluate the performance of various commercial smoke producers, and a number of these machines was on show.

The work on smoking has also led to the development of various new instruments. A simple robust smoke density meter operating on the usual lamp and photocell principle was exhibited together with a modification of it, the 'smoke density integrator', which indicates directly smoke density multiplied by time-a quantity of great importance in smoke curing. Although more recent background work has shown that the invisible vapours in wood smoke are of more importance than the visible particles in giving smoked products their characteristic odour and flavour, smoke density meters are still of very considerable value. A technique for measuring the concentration of vapours was also exhibited.

Much of the work of the Humber Laboratory which has been of the most direct value to the fish industry has depended less on the discovery of new facts than on the practical application of well-established knowledge. For example, very considerable assistance has been given in setting up quality-control schemes which are based on taste panel techniques developed at the Torry Research Station in past years. Similarly, much-needed advice on the best methods of packing fish in ice for inland transport is merely the application to fish of the well-known laws governing the transient state conduction of heat. Work of this nature is extremely necessary in a station of the Department of Scientific and Industrial Research which serves the needs of an industry which as a whole is technically backward, and in which scientific staff are found only in the largest and most progressive companies.
D. L. NICOL

\title{
FOOD AND AGRICULTURE IN DEVELOPING COUNTRIES
}

\begin{abstract}
$\mathrm{O}^{\mathrm{N}}$ October 13 the Nutrition Society held a symposium, at the National Institute for Research in Dairying, Shinfield, Reading, under the chairmanship of the director, Prof. R. G. Baskett, on agricultural problems in developing countries. The latest Food and Agriculture Organization review of food and agxiculture* shows that the developed areas still have an abundance, even a surplus of agricultural products, while malnutrition and hunger are the order of the day in many less-developed countries. The past decade has seen a very considerable expansion in the world output of food. For example, the

* Food and Agriculture Organization of the United Nations, Rome. The State of Food and Agrictllure, 1961. Pp. viii + 177. (Rome: Food and Agriculture Organization of the United Nations; London: and Agriculture Organization of
H.M.S.O., 1961.)
$108 . ; 2$ dollars.
\end{abstract}

average annual combined output of wheat, rice and maize (including the Food and Agriculture Organization estimates for the U.S.S.R. and mainland China) rose from about 470 million long tons in 1948 52 , to about 720 million long tons in 1959. This remarkable technical achievement rests far more on increased efficiency of production than on increases in crop area. The overall food output per head has risen, but this covers dangerous decreases in Latin Araerica and Oceania, and little change in Africa, as well as considerable increases in Europe (where population growth has been slower than elsewhere), North America and the Near East. In the Far East, where food production per head fell sharply during the War years, the pre-war standard, low as it was, 
has been restored by increases in food production of about 3 per cent per annum. The very considerable increases in food production claimed in China since 1950 are perhaps no more than an intensification of this general trend.

In the past two or three years, however, food output has been more static, and in 1961 (including the disastrous harvests reported from China) total production was probably no greater than in 1960 . International trade and co-operation are moving part of the Western surpluses into the needy areas, but there are not enough railway wagons, ships, elevators and sacks in the world to touch more than the fringes of the problem. For the hungry countries, continued increase in their own output, and particularly in yield per acre, is the only answer. Most of them have already done a good deal, as the Food and Agriculture Organization figures show, but the great disparity in yield per acre between the best and the worst indicates that far more could be done, particularly in India and Pakistan, which harbour onequarter of the world's cattle and where the crop yields are among the lowest in the world.

The Nutrition Society meeting devoted itself largely to this question, with particular reference to tropical areas. Prof. L. Dudley Stamp spoke on the climatic limitations to development in the tropics. $\mathrm{He}$ distinguished first between the monotonous climate of the humid equatorial regions and the alternately wet and dry climate of the very diverse regions which he included in the tropics proper. In neither area does lack of heat limit plant growth, but in the latter variability of rainfall, in amount and in timing, is often pronounced. North and south of these regions lies the tropical arid zone, taken by the United Nations Educational, Scientific and Cultural Organiza tion to lie beyond the 20 -in. ( $500 \mathrm{~mm}$.) isohyets.

At tropical temperatures soils weather deeply and organic matter is rapidly oxidized, while leaching removes plant nutrients beyond the reach of crops, though not of trees. Prof. Stamp felt that shifting cultivation, with hoes (and weods) and without ploughs or tractors, might represent the best scientific answer to the land management problem in the humid tropics. (Clearly the many successful examples of plantation production of perennial crops must represent at least an exception to this generalization, though certainly in high rainfall areas the removal of vegetation, even for a very short period, in land clearing, is bound to create difficult or even dangerous hydrographic situations.) In the dry areas, the accumulation of salts and the formation of pans, together with erosion, can produce arid semi-deserts. In all areas of seasonal rainfall the heaviest agricul. tural tasks of the year fall on man and beast when they are weakened by the privations of the hungry season, and during the rains there are risks of flooding. Water control and irrigation, Prof. Stamp believes, are essential to development in all three regions. The indirect consequences of the tropical elimate such as deterioration of stored food, and the heavy burden of insect and other pests and diseases of plants, animals and man, are also important.

To Prof. A. H. Bunting (University of Reading), who spoke next on the problems of improving arable output, the impression left, though perhaps unintentionally, by Prof. Stamp seemed unduly pessimistic. In many developing countries encouraging inereases in food production have been reported, and impressive yields have been achieved in some. There are two parts to the problem of improvement: the intensi- fication of production and the development of new agricultural land.

Apart from water, the tropical environment is by no means inherently unfavourable for crop production. The highest agricultural dry-matter yields so far recorded in the world are in sugar cane in Hawaii (around 30 tons dry matter/acre/year). The poor yields of peasant production must be compared, not with those of modern scientific farming, but with peasant yields in medieval Europe. Intensification is to be sought through improvements in protoplasm, production, and protection. There are many examples of improvement of yield, quality and disease resistance in tropical crops by selection and breeding. Better production often requires better land use, and the abandonment of shifting cultivation, but this can only come as part of a general process of improve. ment, usually on a regional scale. On a smaller scale, improved rotations, fertilizers, timely and sufficiently dense sowing, and the use of mechanization (particularly at times of peak labour input) have all been shown to pay dividends. Crop protection, including weed control, with the help of agricultural chemicals is well established for export crops in many tropical areas. Seed schemes, in which dressed seed of im. proved varieties is supplied at sowing time by an official organization, already exist in cotton and other crops: the general extension of such schemes would be a powerful aid to progress.

The development of new agricultural areas was illustrated by photographs from the Sudan rainlands, where many millions of acres of land suitable for arable production lie unused for lack of perennial water supplies.

Dr. J. C. Shaw (Food and Agriculture Organization), speaking on animal production problems, estimated that the annual deficit of animal protein in human diets (which is especially marked in the Far East) is equivalent to 1.8 million metric tons of non-fat milk solids. A Food and Agriculture Organization panel assessing livestock problems has given the highest priority to nutrition, followed by disease and management, with breeding last. In cattle, better nutrition means better management of better grazing plus the conservation of cereal and legume feeds and of forage. (Clearly this means that animal production, especially in drier areas, depends entirely on successful arable farming, but the converse is not necessarily true, as those who have advocated "ley farming in the tropies" seem to believe.) Much work is needed on the improvement of forage species, particularly legumes, on the intake of food and its nutritional value, and on the nutritional requirements of cattle in the tropics. Since much of the feed in the dry season comes from nutritionally poor materials, means of conserving or increasing their feed value must be sought. For small animals, farming waste products are important, and formula feeds will have to be devised. Breeding, in rigorous climates, should be based first on investigations of the productivity and improvement of the existing livestock, and should not necessarily be based on crossing programmes using improved stock from temperate countries. Generally, in developing countries, the shortage is not of animal agronomists but of scientific information: more modern veterinary schools aure needed.

Dr. Shaw's assessment of the priorities in animal production was closely supported by $\mathrm{Mr}$. T. J. Lansbury, recently of the University College of Ghana. He, too, gave the highest priority to nutrition, which appears far more important in limiting the 
output of West African cattle (and also of goats, sheep and poultry) at present than their inherent characteristics. Drought leads to shortage of feed and of water, and may lead to losses of 25 per cent of live weight in a single season. The improvement of water supplies by conservation requires planned use of grazing, while the problem of dry-season feed supplements has scarcely been tackled, partly because there is little information on the composition of animal feeds in the savannah regions. The West African ox does not seem to possess the superior digestive powers with which it is credited, and indeed digestibility is reduced when animals are fed on a low plane of nutrition, particularly in respect of phosphorus and protein. Basic work on all these matters, which would no doubt include studies of urea and other nonprotein nitrogen sources, is needed on the spot.

Introduced varieties of pigs and poultry can do well in West Africa. Pigmeat is not in demand, but great expansion of egg production is possible if the birds are properly fed and cared for and not regarded as mere scavengers. An industry based on imported chicks is developing, but serious nutritional problems (protein, vitamins $B$ and others, calcium and other minerals) remain to be overcome. An industry for feeding-stuffs could be based on local materials which are at present exported for the formulation of feeds in Europe.

The last speaker, Mr. R. S. Rack, based his contribution on his remarkable work in the practical development of native fishing industries in Northern Rhodesia. His address was notable for its active concern with the human problems of agricultural development. He pointed out that the people of undeveloped countries have their own technical and social adaptations to their environment, and that the technological basis of their economy cannot be altered in isolation from its personal and social context. This difficulty shows itself in attitudes to organization and work discipline (whether selfimposed or not) and to the employment of time, and in the obstacles often presented by traditional habits and customs. The simple poverty of the native fisherman, and his social and family obligations, may prohibit the accumulation of capital; the size of his undertaking may in any event be too small to allow a single technical step (such as the purchase of an outboard motor) unless his whole scale of operation can be altered to take full advantage of it. Other problems include the supply of fish, the availability of technically competent and equipped fishermen, and the existence or possibility of markets and suitable transport. These factors were illustrated by an account of the successful measures taken since 1951 to improve the supply of fish (whether fresh, as a staple food, or dried as a relish in a cereal diet) to the Rhodesian Copper Belt, which involved an ice plant, a boat-building school, a marketing advisory organization and the encouragement of African traders, and is to lead on to a fisheries school which will teach navigation, the handling of powered boats and book-keeping in addition to the techniques of catching and preserving fish. Another example arose from the development of a fishing industry among the traditionally non-fishing Tongas when they were resettled because of the construction of the Karibe Dam, and a third from the improvement of a sardinetype fishery on Lake Tanganyika.

In the discussion following the papers, an interesting food chain involving water hyacinth, pigs and fish was described by Prof. Stamp from Hong Kong, and some disagreement was evident on the usefulness of imported stock in the tropics.

The Food and Agriculture Organization report, already mentioned, also deals with human and organizational problems, on a regional scale, in two special chapters. One, on land reform and institutional change, surveys the situation in the main regions of the world and then discusses particular problems such as tenancy, financial support, marketing, settlement and community development. The second is on the organization of extension education and research in Africa, Asia and Latin America. Taken as a whole, the report is, as usual, a valuable and informative survey.

The meeting, and the report, justify a degree of optimism not only about the technical possibilities but also about the chances that they will be in part realized during the next two or three generations. The social and historical imponderables are too great to make any further prediction useful: but it is impossible to avoid the conclusion that a general limitation of human numbers is ultimately desirable if a measure of dignity and worthiness of human life is ever to be achieved.

A. H. Bunting

\section{SCANNING TECHNIQUES IN BIOLOGICAL AND MEDICAL MICROSCOPY}

\begin{abstract}
A
CONFERENCE on the principles and applications of scanning methods in the microscopy of biological and medical specimens, arranged by the New York Academy of Sciences, was held in the Henry Hudson Hotel, New York, during October 5-6. Fourteen papers were presented in the four sessions of the meeting, and all but one were concerned with optical microscopy, the exception being on electron and X-ray scanning microscopy.

The main group of contributions ranged from the straight application of television in microscopical observation to the design of a complicated flyingspot system for sizing cells. M. J. Kopac (Graduate School of Arts and Sciences, New York University) described the use of closed-circuit television in
\end{abstract}

connexion with the micro-surgical technique he has developed for operating on single cells. At present the micro-instruments, of which there may be as many as eight in use in a single operation, are manipulated by hand. It is planned to adapt the electronic techniques used for tracking targets in the air so as to control the movement of microneedles and micro pipettes with servo-motors.

Scanning techniques are especially useful for cytochemical studies of transient processes in cells. C. N. Loeser and S. S. West (School of Medicine, Western Reserve University, Cleveland, Ohio) have been using a highly sensitive 'Intensifier Image Orthicon' television camera to record fluorescence emission spectra from individual Ehrlich ascites cells, stained 